\title{
Electric current captures top sperm
}

SYDNEY

Fertility researchers have devised a way to isolate high-quality sperm from a sample of semen using an electric current. The team hopes that the method, which has resulted in the birth of a healthy baby, will lead to more efficient in vitro fertilization (IVF) treatments.

${ }^{\text { }}$ We've been separating sperm in the same way since the first IVF baby Louise Brown was born, more than 25 years ago," says Steven Fleming, scientific director of the Westmead Infertility Centre in Sydney. "No one has significantly moved the technology forward, until now." Fleming hopes to collaborate with the researchers who developed the technique in clinical trials of the new method.

During IVF it is important to separate the sperm from the rest of the semen as quickly as possible because the semen contains potentially destructive oxidative chemicals. This is normally done by centrifugation, but the multiple steps necessary take up to an hour and the forces involved can damage the sperm. Centrifugation normally selects for higherquality sperm, as sperm with dense intact heads are separated from the rest. Alternatively, sperm can be selected on the basis of their ability to swim.

But neither method works well when sperm samples have to be taken directly from the

\section{IMAGE \\ UNAVAILABLE FOR COPYRIGHT REASONS}

Current methods to select sperm for IVF are slow and difficult

membrane, leaving the others, and any contaminants, behind.

It is not known why negatively charged sperm have the most intact DNA. Researchers think that negatively charged sialic acid, added during the final stages of sperm production, is an indicator that the sperm has successfully assembled and matured. "It's like the cherry on the cake, says John Aitken, one of the researchers who developed the technique. "Everything else has to have gone absolutely normally for the sperm to get to that point."

The new separation process takes only five minutes, is gentle, and works on sperm taken directly from the testides. It also involves fewer steps than centrifugation, reducing the chance that samples could get mixed up.

testicles. In this case, the resulting sperm aren't motile enough for a swim test and cellular debris makes centrifugation difficult.

The new method, developed by researchers at the University of Newcastle in New South Wales, relies on a technique known as electrophoresis, and the fact that negatively charged sperm have the mostintact DNA (C. Ainsworth et al. Hum. Reprod. 20, 2261-2270; 2005).

Semen is placed in a chamber within a membrane containing pores through which only the sperm can pass. An electric current draws negatively charged sperm across the
Aitken and his colleagues collaborated with experts at an IVF clinic in New South Wales to treat a couple who had been unable to conceive using other methods of sperm separation. "Electrophoresis was tried as a last resort," says Aitken. The couple conceived successfully and a healthy baby was delivered earlier this year. The researchers declined to reveal further details, saying they want to publish the results of the case study, but they plan to seek approval from hospital human ethics review committees to start a clinical trial next year.

Carina Dennis

\section{Australia mooted as dump for world's nuclear waste}

\section{SYDNEY}

Australia should become an international repository for nuclear waste, according to a former prime minister. The idea has outraged environmentalists, but some scientists are giving it cautious consideration.

Robert (Bob) Hawke, prime minister from 1983 to 1991 , made his suggestion to a gathering of graduates in Sydney on 26 September. Australia has an obligation, he says, as one of the world's largest uranium suppliers, to be part of the solution for disposing nuclear waste. "We would be doing a good turn, environmentally, for the world, he told Nature.

Overseas nuclear-power users would pay to ship their waste to Australian shores, where it would then be transported to sites within the vast, sparsely populated regions of Western Aus- tralia or the Northern Territory. Hawke claims that the arrangement would be worth billions to Australia's economy. "It would be an enormous source of income that we could use to address our own environmental problems," he says.

"It's not a far-fetched idea," says nuclear physicist Aidan Byrne, who heads the department of physics at the Australian National University in Canberra. Australia's geological and political stability makes it an attractive site for waste disposal, he says.

Environmentalists disagree. "It's fanciful," says Ben Pearson, an energy campaigner for Greenpeace in Australia, who argues that it would be too dangerous to transport large amounts of nuclear waste around the world. "Ships sink; accidents happen," he says.

Hawke plans to rally further discussion on the topic. "I want to get a sensible debate

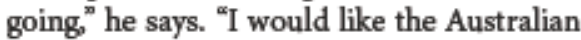
scientific community to put resources into confirming the safest sites."

The proposal will struggle to get political support; the federal and state governments cannot even agree on where to store the nation's own small amount of low-level nuclear waste. And several states have legislation that bans the import of nuclear waste.

But Byrne thinks attitudes may be shifting. "If Hawke had suggested this a year or so ago, it would have been seen as ridiculous. But the nuclear debate has come a long way." He adds, "if Australia is to be part of the nuclear cycle as a supplier, then we need to be thinking about waste disposal as well".

Carina Dennis 